\title{
CONGENITAL HIGH TYPE ANORECTAL MALFORMATION (RECTO-VAGINAL FISTULA) IN A 7 MONTHS OLD GIRL: A CASE REPORT
}

Anderson Kharnaior ${ }^{1}$, Suiyibangbe ${ }^{2}$, K. Lokendra ${ }^{3}$, S. Ranita Devi ${ }^{4}$, G. S. Moirangthem ${ }^{5}$

\section{HOW TO CITE THIS ARTICLE:}

Anderson Kharnaior, Suiyibangbe, K. Lokendra, S. Ranita Devi, G. S. Moirangthem. "Congenital High Type Anorectal Malformation (Recto-Vaginal Fistula) in a 7 Months Old Girl: A Case Report". Journal of Evolution of Medical and Dental Sciences 2015; Vol. 4, Issue 34, April 27; Page: 5937-5941, DOI: 10.14260/jemds/2015/868

ABSTRACT: A congenital recto-vaginal fistula is a high type of ARM characterized by the abnormal connection of the rectum to the vagina. High type anorectal malformations (ARM) are extremely rare variants in the spectrum of anorectal deformities. Delayed presentation of a patient with high anorectal malformation is rare. The unusually rare and late presentation of this case highlights the need to generate awareness of the general population, the medical fraternity about common congenital anomalies and the need for efficient referral system to a tertiary centre.

KEYWORD: Anorectal malformation (ARM), High type recto-vaginal fistula, Posterior saggital anorectoplasty (PSARP).

INTRODUCTION: Anorectal malformation (ARM) displays a wide range of severity from imperforate anal membrane to complete caudal regression.[1] Embryologically, the caudal end of the hindgut dilates to form the cloaca. By six weeks of gestation, the urorectal septum moves caudally to divide the cloaca into the anterior urogenital sinus and the posterior anorectal canal. Failure of this septum to form results in a fistula between the bowel and urinary tract (in boys) or the vagina (in girls)..[2] $\mathrm{A}$ majority of patients with ARM present immediately after birth. ${ }^{[3]}$ In developing countries like India, where a significant number of births are home deliveries, poverty and illiteracy contribute to a significant number of patients with ARM present to a referral center later during infancy or even late childhood.

CASE REPORT: A 7 months old female baby from a low socio-economic background residing in Churrachanpur, Manipur, India was brought to us by her parents with the complaints of absent anal opening and passage of flatus and faeces through the vagina. The baby was a full term, vaginal home delivery and was exclusively on breast feeds since birth. On examination, the child is afebrile, active, alert, well-nourished and weight 9kgs. Her development milestones were normal for her age. Her abdomen was soft but distended. She had an associated mild ventricular septal defect.

Routine blood investigations were all normal. Chest X ray (PAV) showed normal study, X-ray spine and Ultrasound whole abdomen did not reveal any associated anomalies. 2D echocardiography shows ventricular septal defect with LVEF of $56 \%$.

In view of the abdominal distension, an ascending loop colostomy was done as the initial procedure. A distal colostogram before the definitive repair showed normal calibre distal colon and the presence of a fistulous tract from the rectum to the upper end of the posterior vaginal wall.as shown in Fig. 1. 


\section{CASE REPORT}

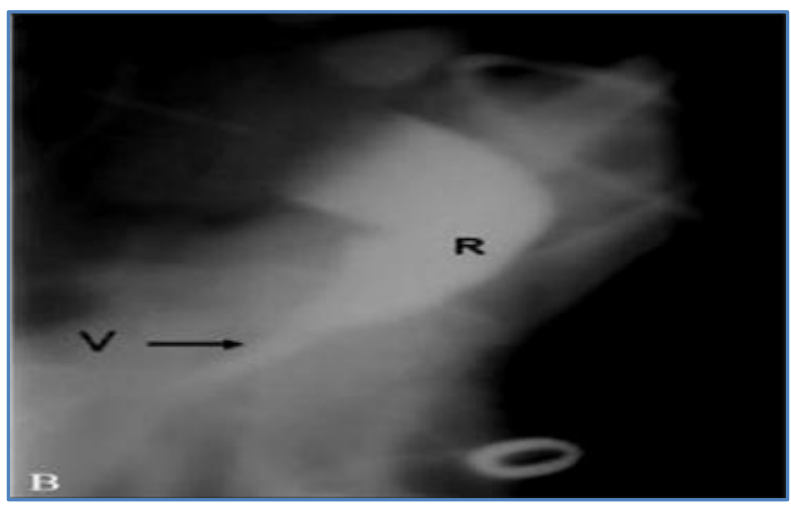

\section{Fig. 1: Distal Cologram showing the distal colon opening into upper end of the vagina suggestive of a high type ARM (Recto-vaginal fistula).}

The post-operative period after the first stage procedure was uneventful. Patient was discharged after the $7^{\text {th }}$ post-operative day. The parents were advised to report after twelve weeks for the second stage procedure but they reported only sixth months later. Since there was a good bowel decompression through the stoma, the second stage posterior sagittal anorectoplasty (PSARP) was performed. Intra-operatively, a large recto-vaginal fistula was found as shown in Fig. 2. Fig. 3 shows the creation of a new anal opening and the completion of PSARP. The post-operative period was uneventful. Two weeks after PSARP, the baby was started on an anal dilatation regime. The same was taught to both the parents so that they continue doing that at home on discharge. The patient was then discharged on the $10^{\text {th }}$ post-operative day. Six weeks after PSARP, the stoma was closed. All the surgical procedures were uneventful and at present the patient is doing well and is on regular follow-up.

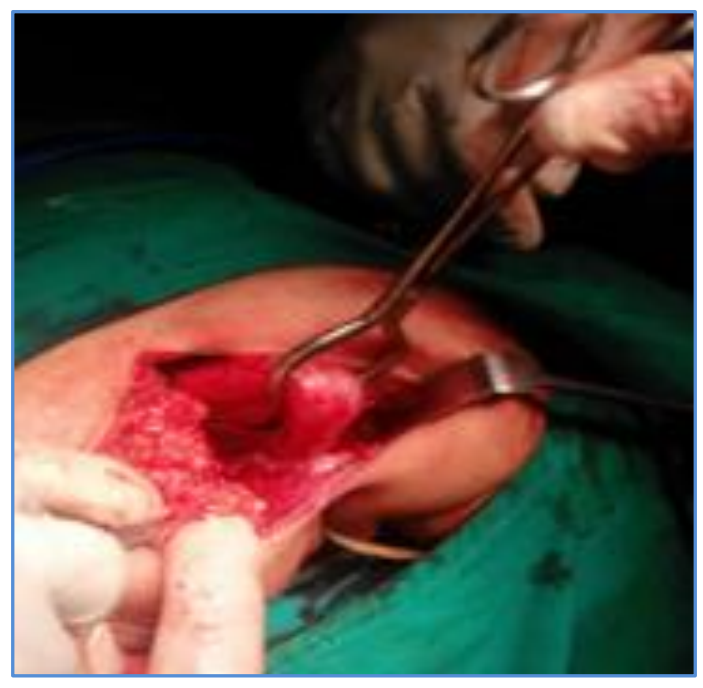

Fig. 2: Intra-operative photograph showing a large recto-vaginal fistula during PSARP 


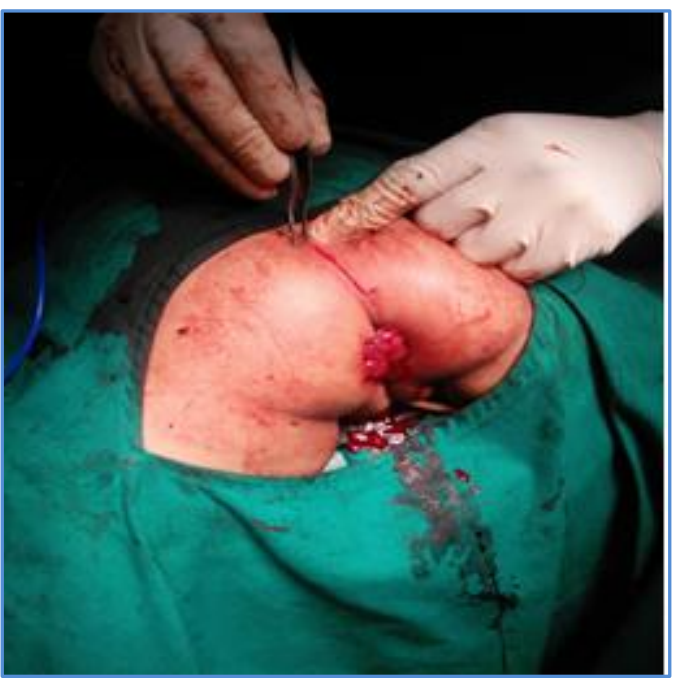

Fig. 3: Intraoperative photograph showing creation of a new anal opening and the completion of PSARP

DISCUSSION: In developed countries, delayed presentation of uncorrected ARM is an uncommon event because of routine neonatal examination before discharge from hospitals. In developing countries like India, a large number of births are home deliveries, assisted by untrained or nonmedical persons.[4] Therefore, ARMs may be missed at birth and initial presentation may be during infancy or even later in childhood, especially if there is no acute intestinal obstruction or associated congenital malformations.

Congenital H-type recto-vaginal fistulas are extremely rare entities in the spectrum of anorectal malformations constituting $0.7 \%$ of the malformations seen in females.[5] Since the first description by Bryndorf and Madsen in 1960,[6] very few cases have been documented in the literature mostly a recto-vestibular fistula but not a recto-vaginal fistula.

A study by Kim HL et al noticed[7] that all patients with delayed diagnosis had low type ARM. In previously published literature, most of the patients of ARM with delayed diagnosis were female patients with vestibular fistulas or male patients who had low type ARM. However, this was not the case in our patient who presented with a high type ARM.

Delay in diagnosis of ARM may lead to early complications like abdominal distension, vomiting, dehydration, intestinal perforation, respiratory distress, sepsis and even death[8,9] Late complications like megarectum, megacolon require decompression in the form of a stoma and may cause poor functional outcome of the definitive repair.[10] The absence of the symptoms in our patient despite high type of ARM is attributed to the large fistulous communication between the rectum and the vagina.

CONCLUSION: Delayed presentation of a patient with high type ARM is rare. This case is unusually rare because it is perharps the first case in literature presenting late at 7 months in a female child with a high type ARM (recto- vaginal fistula) with imperforate anus and associated cardiac anomaly (ventricular septal defect). The other case mentioned in the literature is of a 9 years old girl with large recto-vaginal fistula and a normal anal opening passing stool both from the vagina and anus with no other associated anomaly.[11] 
This case highlights the fact that even with late presentation of high type ARM (recto-vaginal fistula in our case) the three stage operative procedure is feasible which is why we first did a diversion colostomy followed by the second stage definitive repair, i.e, the PSARP operation and the third stage colostomy closure. This case also highlights the fact that educating and creating awareness to the general population about common congenital anomalies should be taken as a priority by health care providers especially in remote villages of India where literacy level is at its lowest point. The traditional birth attendant or 'dais' who conduct home deliveries should also be trained to recognise congenital anomalies which can go a long way in early diagnosis and management of such cases.

\section{REFERENCES:}

1. Eltayeb AA. Delayed presentation of anorectal malformations: The possible associated morbidity and mortality. Pediatr Surg Int 2010; 26: 801-6.

2. Chung DH. Paediatric surgery. In: Townsend CM, Beauchamp RD, Evers BM, Mattox KL. Sabiston Textbook of Surgery. 19th edition. Philadelphia: Elsevier Saunders; 2012.p.1849.

3. Pandey A, Gangopadhay AN, Kumar V, Sharma SP. High anorectal malformation in a five monthold boy: A case report. J Med Case Reports 2010; 4: 296.

4. Sinha SK, Kanojia RP, Wakhlu A, Rawat JD, Kureel SN, Tandon RK. Delayed presentation of anorectal malformations. J Indian Assoc Pediatr Surg 2008; 13: 64-8.

5. Lawal TA, Chatoorgoon K, Bischoff A, Pena A, Levitt MA. Management of H-type rectovestibular and rectovaginal fistulas. J Pediatr Surg 2011; 46: 1226-30.

6. Bryndorf J, Madsen CM. Ectopic anus in the female. Acta Chir Scand 1960; 118: 466-78.

7. Kim HL, Gow KW, Penner JG, Blair GK, Murphy JJ, Webber EM. Presentation of low anorectal malformations beyond the neonatal period. Pediatrics 2000; 105: E68.

8. Haider N, Fisher R: Mortality and morbidity associated with late diagnosis of anorectal malformations in children. Surgeon 2007, 5: 327-330.

9. Lindley RM, Shawis RN, Roberts JP: Delays in the diagnosis of ano-rectal malformations are common and significantly increases serious early complications. Acta Paediatrica 2006, 95: 364-368.

10. Rathod KJ, Bawa M, Mahajan JK, Samujh R, Rao KLN. Delayed presentation of anorectal malformations: Need of community awareness. Indian J Public Health 2011; 55: 135-6.9.

11. Bianchini M.A. et al. A rare anorectal malformation: a very large H-type fistula. Pediatric Surgery International 2001; 17: 649-651. 


\section{AUTHORS: \\ 1. Anderson Kharnaior \\ 2. Suiyibangbe \\ 3. K. Lokendra \\ 4. S. Ranita Devi \\ 5. G. S. Moirangthem}

\section{PARTICULARS OF CONTRIBUTORS:}

1. Post Graduate Trainee, Department of Surgery, Regional Institute of Medical Sciences, Imphal, Manipur.

2. Post Graduate Trainee, Department of Surgery, Regional Institute of Medical Sciences, Imphal, Manipur.

3. Senior Resident, Department of Surgery, Regional Institute of Medical Sciences, Imphal, Manipur.

FINANCIAL OR OTHER

COMPETING INTERESTS: None
4. Professor, Department of Surgery, Regional Institute of Medical Sciences, Imphal, Manipur.

5. Professor \& HOD, Department of Surgery, GI \& MAS, Regional Institute of Medical Sciences, Imphal, Manipur.

\section{NAME ADDRESS EMAIL ID OF THE CORRESPONDING AUTHOR:}

Dr. Anderson Kharnaior,

P. G. Gents Hostel No. 1,

Room No. 45, RIMS,

Imphal, Manipur.

E-mail: umlaper@gmail.com

Date of Submission: 30/03/2015.

Date of Peer Review: 31/03/2015.

Date of Acceptance: 15/04/2015.

Date of Publishing: 27/04/2015. 